\title{
Light-Triggered Boost of Activity of Catalytic Bola-Type Surfactants by a Plasmonic Metal-Support Interaction Effect
}

\author{
Sebastian Sutter, ${ }^{\dagger}$ Bastian Trepka, $^{\dagger}$ Stephan Siroky, $^{\dagger}$ Kay Hagedorn, $^{\dagger}$ Sebastian Theiß, ${ }^{\dagger}$ Peter Baum, ${ }^{\dagger}$ \\ and Sebastian Polarz $*, \dagger$
}

${ }^{\dagger}$ Functional Inorganic Materials Group, Department of Chemistry and ${ }^{\ddagger}$ Department of Physics, University of Konstanz, Universitätsstrasse 10, 78457 Konstanz, Germany

Supporting Information

ABSTRACT: The maximization of activity is a general aim in catalysis research. The possibility for light-triggered enhancement of a catalytic process, even if the process is not photochemical in nature, represents an intriguing concept. Here, we present a novel system for the exploration of the latter idea. A surfactant with a catalytically active head group, a protonated polyoxometalate (POM) cluster, is attached to the surface of a gold nanoparticle (Au NP) using thiol coupling chemistry. The distance of the catalytically active center to the gold surface could be adjusted precisely using surfactants containing hydrocarbon chains $\left(\mathrm{C}_{n}\right)$ of different lengths $(n=4-10)$. Radiation with VIS-light has no effect on the catalytic activity of micellar aggregates of the surfactant. The situation changes, as soon as the surfactants have been attached to the Au NPs. The catalytic activity could almost be doubled. It was proven that the effect is caused by coupling the surface plasmon resonance of the Au NPs with the properties of the POM head group. The improvement of activity could only be observed if the

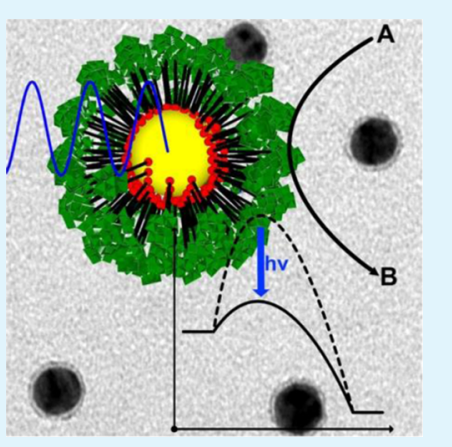
excitation wavelength matches the absorption band of the used Au NPs. Furthermore, the shorter the distance between the POM group and the surface of the NP, the stronger is the effect. This phenomenon was explained by lowering the activation energy of the transition state relevant to the catalytic process by the strong electric fields in the vicinity of the surfaces of plasmonic nanoparticles. Because the catalytic enhancement is wavelength-selective, one can imagine the creation of complex systems in the future, a system of differently sized NPs, each responsible for a different catalytic step and activated by light of different colors.

KEYWORDS: surfactants, polyoxometalates, photocatalysis, self-assembly, nanoparticle capping agents

\section{INTRODUCTION}

Surfactant-like compounds are not only key components in the membranes of any biological cell, but the amounts of surfactants prepared by the chemical industry each year $(\approx 2$ $\left.\times 10^{7} \mathrm{t} / \mathrm{a}\right)$ also reflect the enormous importance of this special kind of functional molecules. The classic case is represented by compounds with a water-soluble head group attached to an oilsoluble alkyl tail. The described molecular architecture is responsible for the emergence of amphiphilic properties, selfassembly to higher order structures (e.g., micelles and liquid crystals), and the broad range of applications, such as in detergents, emulsification agents, and in phase-transfer catalysis. ${ }^{1}$ Surfactants are also used frequently in nanoscience as capping agents e.g., for the control of nanoparticle growth and colloidal stabilization. ${ }^{2}$ The integration of inorganic moieties has proven to be a powerful strategy for the development of novel surfactants equipped with more complex profiles and additional functionalities, for instance, catalytic properties. $^{3-7}$ Like for any other catalytic system as well, maximization of activity is one of the main targets in research. An intriguing question is: after the molecular structure of a catalytic surfactant has been optimized if additional measures exist, how to improve the activity further?
A unique way to maximize the activity known in the literature on heterogeneous catalysis is the so-called strong metal-support interaction, a phenomenon describing that certain combinations of metals on immobilized particular metal oxides are orders magnitudes more active than others. ${ }^{8}$ Nanoscale dimensions of the metals (e.g., Au) were first and foremost considered important because of the enhanced surface to volume ratio. However, in some recent reports, scientists have discussed the role of plasmonic effects regarding the enhancement of photocatalytic activity in hybrid materials between gold nanostructures and metal oxides. ${ }^{9-13}$ Solarska et al. used this concept in polyoxometalate-gold hybrids. ${ }^{14}$ Polyoxometalates (POMs) are frequently described as molecular oxides, and one of the numerous, valuable features of POMs is catalytic activity. ${ }^{15,16}$ Solarska et al. reported an astonishing improvement of the performance of photoanodes used for the water-splitting reaction, which was modified by $\mathrm{Au}$ NPs and POMs. The combination of catalytically active surfactants with gold nanoparticles could be a general and elegant way for optimization of catalytic surfactants as well.

Received: February 28, 2019

Accepted: April 5, 2019

Published: April 5, 2019 
Scheme 1. Synthetic Sequence Leading to the Polyoxometalate-Thiol Surfactants with Bola Design $(n=1-7)$. TMA $\cong$ Tetramethylammonium

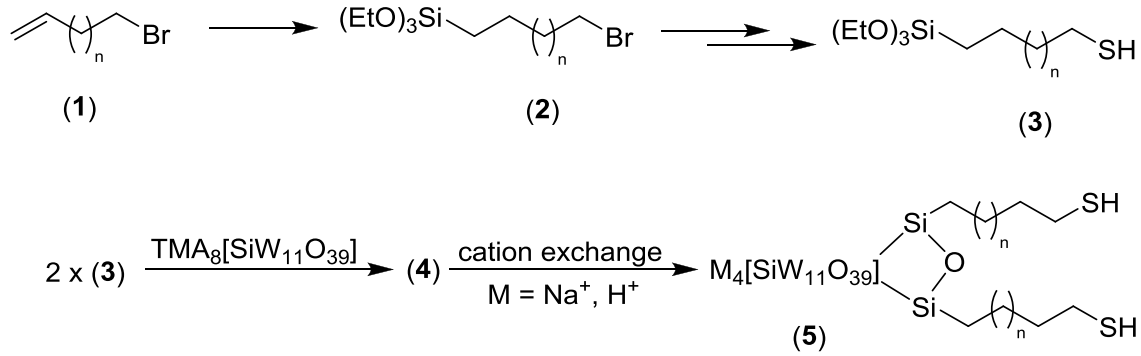

Based on the given arguments, surfactants with molecular oxides (POMs) as constituents will be valuable model systems for answering the latter question. ${ }^{17}$

There was already significant activity in the past on POMorganic hybrid materials in general and concerning those with amphiphilic properties in particular. ${ }^{18-21} \mathrm{~A}$ very good introduction to the topic can be found in the seminal review published by Cronin et al. ${ }^{22}$ The key for the success was that a variety of strategies have been developed for the organic modification of POM clusters. ${ }^{16,23}$ Liu's group was very successful in using the mentioned modification strategies to achieve multifunctional amphiphiles containing molybdate (Anderson), ${ }^{24}$ tungstate (Dawson), ${ }^{25,26}$ and also vanadate systems. $^{27}$ In the 1990s, Judenstein and Hill's group established the basis for lacunary W-Keggin clusters as constituents. $^{28,29}$ This enabled our group to concentrate on surfactants with an $\left[\mathrm{EW}_{11} \mathrm{O}_{39}\right]^{n-}$ (lacunary Keggin) head group $(\mathrm{E}=\mathrm{P}, \mathrm{Si}, \mathrm{B}) .^{30-33}$ The hydrophobic entity in the latter surfactants is an alkyl group, and it can thus not interact specifically with inorganic surfaces. However, it is well-known in the literature that organic thiols do strongly interact with metallic surfaces and eventually form the so-called selfassembled monolayers on gold (SAMS). ${ }^{34}$ Although the gold surfaces are typically flat for SAMS, organic thiols also bind very well to curved surfaces such as in gold nanoparticles ( $\mathrm{Au}$ NPs). ${ }^{35}$ Cabuil and co-workers or Kapoor et al. used this concept for the immobilization of POMs on $\mathrm{Au} \mathrm{NPs,}{ }^{36,37}$ and later De bruyn et al. reported an extension to Pd NPs. ${ }^{38}$ There are further reasons why $\left[\mathrm{SiW}_{11} \mathrm{O}_{39}\right]^{4-}$-based surfactants modified with alkyl chains containing a terminal thiol group, as shown in Scheme 1, represent valuable building blocks. The thiol group can undergo various modification reactions like the thiol-ene click reaction, ${ }^{39}$ which should enable to introduce several alternative functions as a terminal group of the surfactant. Considering that two thiols can be coupled to disulfide bridges, one can think of POM-surfactant networks. Thiols can also be oxidized to sulfonic acid derivatives, and this would lead to a bolaform surfactant with two highly acidic end groups.

Here, we will present a systematic series of surfactants with the $\left[\mathrm{SiW}_{11} \mathrm{O}_{39}\right]$ head group and alkylthiol side chain(s) of varying lengths. The surfactant properties of the compounds will be compared to each other, followed by investigating their ability to stabilize the surfaces of Au NPs. Finally, a reaction catalyzed by the protonated $\left[\mathrm{SiW}_{11} \mathrm{O}_{39}\right]$ head will be performed and what the effect of radiation with different wavelengths is will be studied.

\section{RESULTS AND DISCUSSION}

The surfactants were prepared as shown in Scheme 1. For further details, see the experimental part. First, an ethoxysilane functionality was introduced into the $\alpha$-, $\omega$-bromoalkene ( 1 ) by catalytic, anti-Markovnikov hydrosilylation. In a second step, bromine was substituted by thioacetate, followed by its reduction to the thiol function. Finally, compound (3) was reacted with a lacunary POM species and tetramethylammonium (TMA) as a counter ion. The nomenclature of the compounds is used as follows: "TMASiC 10 ", for instance, stands for the compound $\left(\mathrm{N}\left(\mathrm{CH}_{3}\right)_{4}\right)_{4}\left[\mathrm{SiW}_{11} \mathrm{O}_{40}\right](\mathrm{Si}$ $\left.\left(\mathrm{CH}_{2}\right)_{10} \mathrm{SH}\right)_{2}$.

The analysis of $\mathrm{TMASiC}_{10}$ is discussed here as an exemplary case (see also Supporting Information Figure S1 and Table 1). In electrospray-ionization mass spectrometry (ESI-MS), several signals can be assigned clearly to the desired compound. Most importantly, at $1092 \mathrm{~g} / \mathrm{mol}$, the molecular peak $\left[\mathrm{M}^{5-}(\mathrm{TMA})_{2}\right]^{3-}$ can be identified. As expected, two signals are found in ${ }^{29} \mathrm{Si}$ NMR spectroscopy, one at -85.09 $\mathrm{ppm}$ characteristic for the $\mathrm{Si}$ atom bound inside the cluster and one with roughly twice the intensity at $-52.18 \mathrm{ppm}$ for the alkylsilane species. The ${ }^{183} \mathrm{~W}$ NMR spectrum displays the characteristic pattern of an organically functionalized monolacunary tungstate Keggin species. ${ }^{40}$ Since the solubility in water is low for $\mathrm{TMA}^{+}$compounds and acidic heads are needed for the catalytic experiments, ion exchange chromatography was performed $\left(\mathrm{TMA}^{+}\right.$to $\mathrm{Na}^{+}$or $\left.\mathrm{H}^{+}\right)$. After cation exchange, there is only a small shift in ${ }^{29} \mathrm{Si}$ NMR signals indicating the integrity of the surfactant and the POM head. Analytical data are summarized in Figures S2 and S3. Final evidence for the successful preparation of the target compounds is achieved by ESI-MS. For instance, the signal shown in Figure 1a can be unambiguously assigned to the doubly charged ion $\left[\mathrm{NaH}\left[\mathrm{SiW}_{11} \mathrm{O}_{40}\right]\left(\mathrm{Si}\left(\mathrm{CH}_{2}\right)_{10} \mathrm{SH}\right)_{2}\right]^{2-}$. The acidic character of the compounds with protons as counter ions is proven by recording a titration curve in water as shown in Figure S3. Surfactants with shorter alkyl chains were prepared in analogy and for proof of concept. Figure 1c shows the ESI-MS pattern of another member of the series with $n=4$.

Surface activity and formation of aggregates in solution are two typical features of surfactants. Concentration-dependent surface tension measurements obtained using the Wilhelmy plate method (Figure S4) confirm activity at the air/water interface. Since POM-surfactants tend to interact strongly with the plate used in our set-up, ${ }^{30,32,33,41,42}$ which could have an influence on the reliability of the data, we have applied the pendant drop method as an independent method (Figure 2a). $\mathrm{NaSiC}_{4}$ displays no surface activity. The hydrocarbon chain is obviously too short, so the compound lacks amphiphilic properties. Therefore, $\mathrm{SiC}_{4}$-based compounds were not 


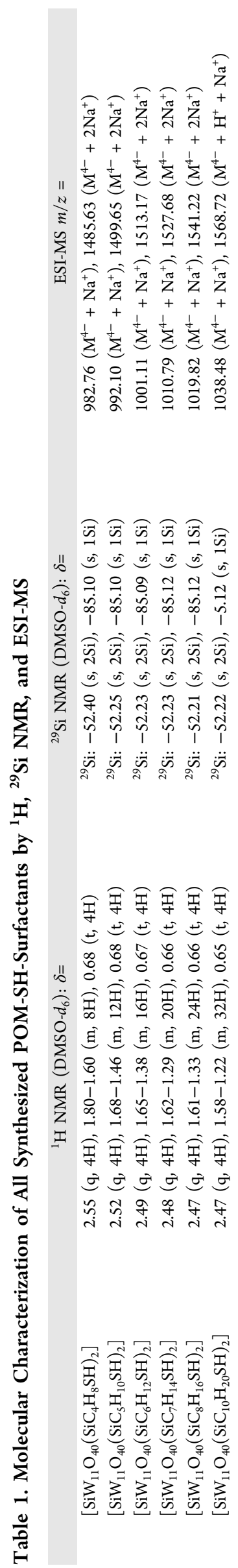

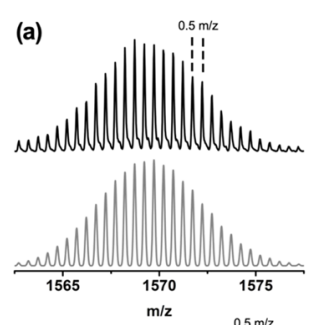

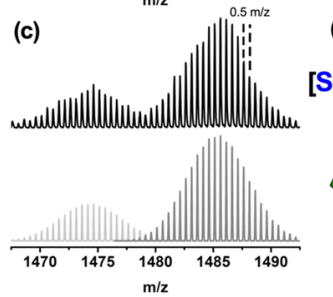

(b)

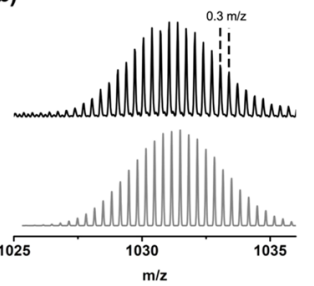

(d)
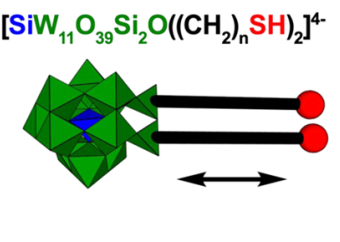

Figure 1. Excerpts of the ESI-MS patterns; black = measured pattern of (a) $\mathrm{NaSiC}_{10}$; gray = signal calculated for the ion $[\mathrm{NaHM}]^{2-}$. (b) $\mathrm{HSiC}_{10}$; gray = signal calculated for the ion $[\mathrm{HM}]^{3-}$. (c) $\mathrm{NaSiC}_{4}$; gray $=$ signal calculated for the ion $\left[\mathrm{Na}_{2} \mathrm{M}\right]^{2-}$, and light gray = signal calculated for the ion $[\mathrm{NaHM}]^{2-}$. (d) Molecular architecture of the synthesized surfactants; $n=4,5,6,7,8,10$.

considered anymore in the following. The drop of surface tension at higher concentrations for compounds $\mathrm{NaSiC}_{n}$ with $n$ $\geq 5$ points to the population of the air/water interface, which is expected for surfactants. However, none of the surfactants could reach minimal surface tension. This is because of the high charge of the head group ${ }^{33}$ and the resulting electrostatic repulsion. Nevertheless, dynamic light scattering (DLS) indicates that aggregates are already present in solution (Figure 2b). The aggregates formed by $\mathrm{NaSiC}_{5}$ have a size in the range expected for micelles. With an increasing packing parameter, the aggregates become significantly larger. For $\mathrm{C}_{10}$, there seems to be a transition, because presumably, a phase with lamellar characteristics becomes more stable. The size of the aggregates was confirmed by transmission electron microscopy (TEM) (Figure $2 \mathrm{c}-\mathrm{e}$ ) and the presence of tungsten in these aggregates is shown by energy-dispersive $\mathrm{X}$-ray spectroscopy (EDX) given in Figure S5.

There are two ways for obtaining the required Au NPs covered by $\mathrm{SiC}_{n}$ surfactants. Either the surfactants act as a capping agent during nucleation and growth of $\mathrm{Au}^{037}$ or they can exchange the capping agent from preformed Au NPs. Figure S6 shows the result of a photoreduction synthesis approach using $\mathrm{AuCl}_{4}^{-}$as a precursor and $\mathrm{NaSiC}_{10}$ as a surfactant. Because the particles are still polydisperse in size and shape, and even in an ideal case, each surfactant would lead to differently sized Au NPs, we decided that it is not worth investing substantial work in optimizing the nanoparticle synthesis protocol further. Instead, we prepared $\mathrm{Au}^{0}$ nanoparticles by a known, citrate-based method. ${ }^{43}$ Afterward, Na/ $\mathrm{HSiC}_{n}$ was added and the success of the required exchange process is proven by high-resolution (HR) TEM/EDX as shown in Figure 3. Each of the Au nanoparticles is surrounded by a thin, noncrystalline layer. The substantial imaging contrast is a first sign for the presence of heavy atoms such as W. In images with lower magnification (Figure 3a), one can even see a dark rim caused by the high electron density of $\mathrm{W}$ in the head group region. Unfortunately, in the HRTEM image (Figure $3 \mathrm{~b}$ ), the head group zone is not imaged anymore, because the focus has been set on the lattice planes of the Au NP and the electron beam penetrates multiple surfactant heads simulta- 

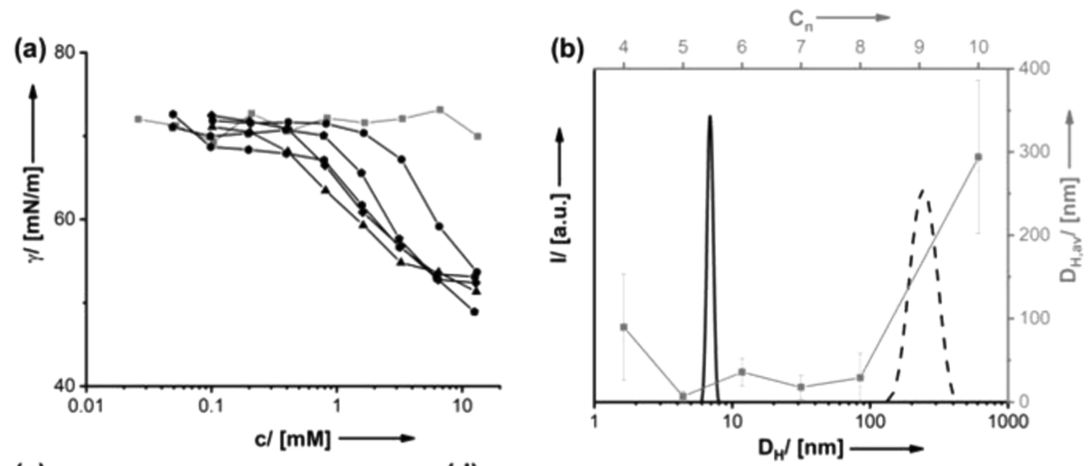

(c)
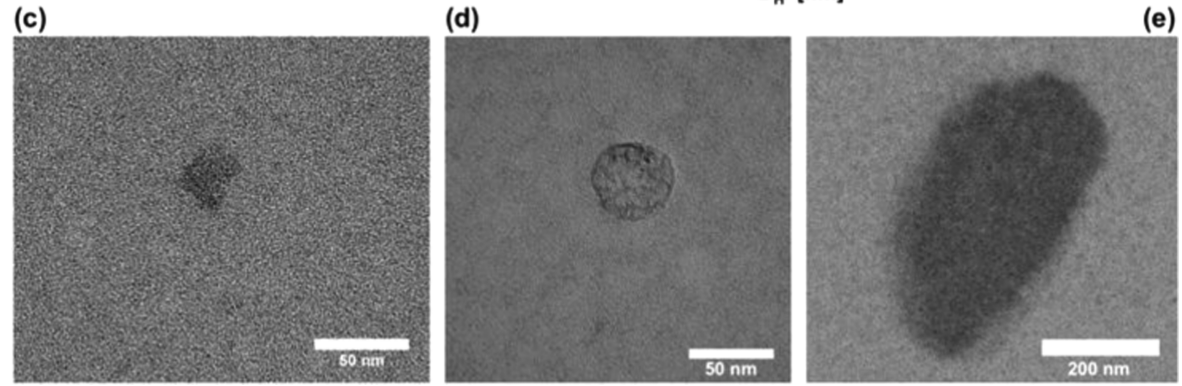

Figure 2. (a) Concentration-dependent surface tension measurements determined by the pendant drop method. Gray squares $=\mathrm{NaSiC}_{4}$, black circles $=\mathrm{NaSiC}_{5}$, triangles $=\mathrm{NaSiC}_{6}$, hashes $=\mathrm{NaSiC}_{7}$, hexagons $=\mathrm{NaSiC}_{8}$, pentagons $=\mathrm{NaSiC}_{10}$. (b) Representative aggregate size distribution curves (black) determined from $\mathrm{DLS}$ of $\mathrm{NaSiC}_{5}$ (solid line) and $\mathrm{NaSiC}_{10}$ (dashed line). Dependence of aggregate size on hydrocarbon chain length $\mathrm{C}_{n}$ (gray). TEM micrographs of a solution of $\mathrm{NaSiC}_{5}$ (c), $\mathrm{NaSiC}_{6}(\mathrm{~d})$, and $\mathrm{NaSiC}_{10}$ (e) deposited on a carbon-coated grid.

neously due to imperfect alignment of the particle. Final confirmation comes from line-scan EDX (Figure 3c), showing the presence of $\mathrm{W}$, and thus the surfactants at the surfaces. Because the thickness of the layer fits to a monolayer of $\mathrm{NaSiC}_{10}$, we can assume that the surfactant binds by means of the thiol group to the gold surface. Decorating the $\mathrm{Au}$ NPs with the surfactant is also confirmed by a small shift $(\Delta \lambda=6$ $\mathrm{nm})$ of the surface plasmon resonance band $\left(\lambda_{\max }=528 \mathrm{~nm}\right)$ after the exchange process. This shift is expected because the dielectric constant of the ligand shell is now different and the electron density of the $\mathrm{W}$-containing surfactants is much higher than for citrate.

Protonated forms of POMs can act as Brønsted acid catalysts for diverse reactions. ${ }^{44}$ Therefore, and because the protonated forms of the surfactants have also proven to be acidic (Figure $\mathrm{S} 3$ ), we have used $\mathrm{HSiC}_{10}$ for the Fischer esterification of 3-phenylpropionic acid with methanol as a test reaction (Figure 4a). The conversion was monitored by quantitative analysis of ${ }^{1} \mathrm{H}$ NMR spectra (Figure S8). The importance of the protic form is also documented by the fact that only $\mathrm{HSiC}_{10}$ is able to catalyze the reaction, whereas $\mathrm{NaSiC}_{10}$ is inactive. $\mathrm{HSiC}_{10}$ remains active when immobilized at the surfaces of the Au NPs (Figure $4 \mathrm{~b}$ ). The high charge of the POM (-4; Figure 4) makes sure that the protons remain in close vicinity of the head group region even in water.

The catalytic tests were repeated while irradiating the sample with light for both systems (free surfactants and immobilized to Au NPs). The design of the self-made photoreactor design is shown in Figure S9 and the calculation procedure of turnover numbers (TON) is described in Figure S10. It is important to note that the reaction was performed under strict isothermal conditions for excluding any heating effect caused by radiation (see experimental details). The conversion does not differ for the free $\mathrm{HSiC}_{10}$ as a catalyst, whether the reaction is performed in light or not (Figure 4a). This result is expected since $\mathrm{HSiC}_{10}$ does not absorb light in the VIS region (Figure S3d). The behavior changes when $\mathrm{HSiC}_{10}$ is attached to the $\mathrm{Au}$ NPs ( $\left.\mathrm{HSiC}_{10} @ A u N P\right)$. VIS radiation (white light) of the latter system leads to a large increase in catalytic efficiency (Figure 4b). We have checked that the catalyst remains unaltered during the catalytic reaction (Figure S11). UV/vis spectra and line-scan EDX measurements are the same before and after catalysis, showing that the POM-surfactant is still attached to the $\mathrm{Au}$ NPs. The turnover number (TON) is a linear function of time in both cases, "dark" and "bright" (Figure S12). Thus, the catalytic activity for each system probably does not change over time, but the difference in slopes is caused by higher catalytic activity in the presence of light.

For testing the hypothesis, the noted effects are caused by an interaction with the plasmonic nanoparticle, we also tested if similar effects are observed and if Au NPs and a reference heteropoly acid $\mathrm{H}_{8} \mathrm{SiW}_{11} \mathrm{O}_{39}$ is present, but the latter is not attached to the particles (see Supporting Information Figure S13c). Because the esterification reaction is catalyzed by protons, there is slow conversion, but the values remain in a region comparable to Figure $4 \mathrm{~b}$ for $\mathrm{HSiC}_{10}$ in the absence of $\mathrm{Au}$ NPs. Two further parameters were addressed: (i) distance-there must be an effect of the surfactant chain length because this will alter the distance of the catalytically active POM head group to the surface of the Au NPs. (ii) Light-because the plasmon resonance band of the Au NPs used here is found at $528 \mathrm{~nm}$ (Figure 4d-inlet), green light lead to a maximal enhancement, whereas other wavelengths should not influence the catalytic efficiency at all or at least to a much lower extent.

The catalytic tests were repeated for a series of compounds differing systematically in the hydrocarbon chain length (Figure $4 c-e ;$ Table S1). The catalytic activity difference in the presence of light becomes more marked for shorter chains $\mathrm{C}_{n}$. For $\mathrm{HSiC}_{5}$, the light-induced catalytic enhancement 


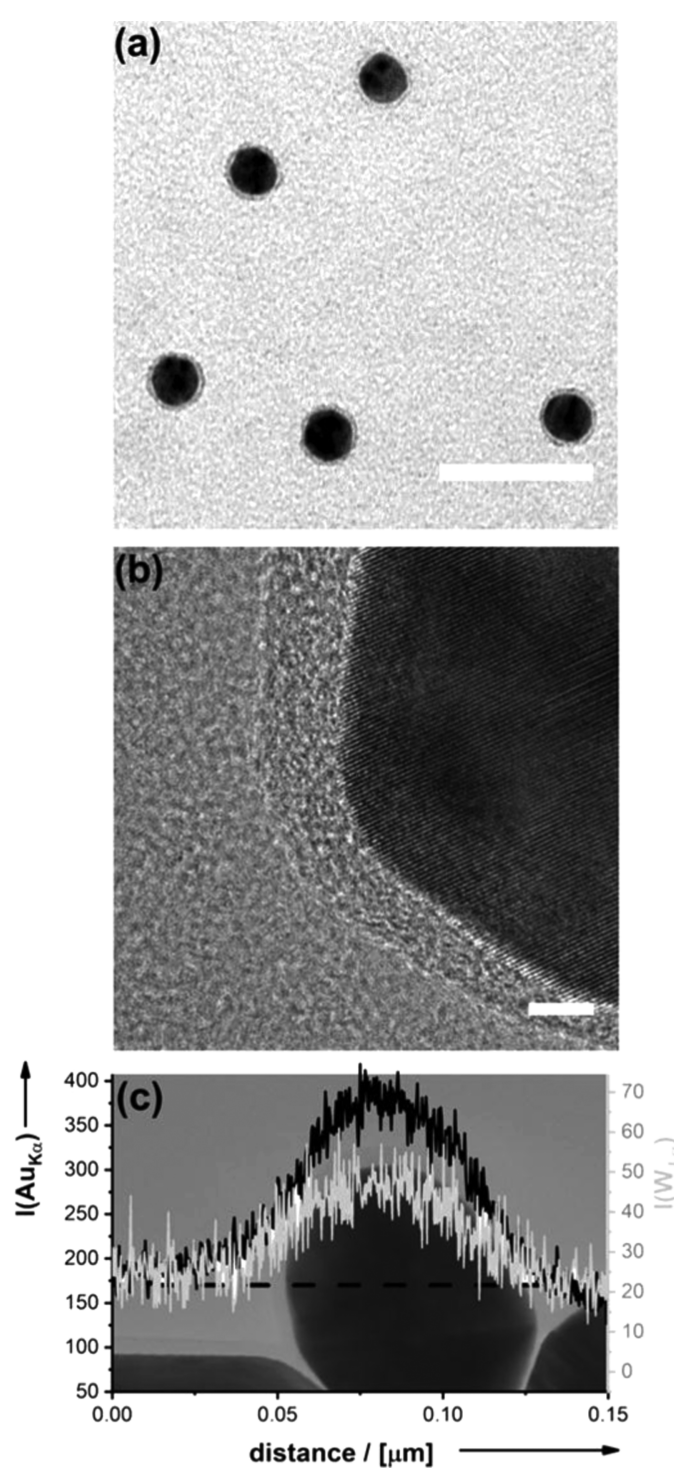

Figure 3. TEM (a; scale bar $50 \mathrm{~nm}$ ) and HRTEM (b; scale bar 2.5 $\mathrm{nm}$ ) images of $\mathrm{Au}$ nanoparticles obtained after surface exchange with $\mathrm{NaSiC}_{10}$. (c) Line-scan EDX analysis (black = Au; gray $=\mathrm{W}$ ).

reaches $150 \%$, meaning that it is more than two times more active than in the dark. For final proof of our hypothesis, the experiments were repeated using monochromatic red (630 $\mathrm{nm})$, green $(530 \mathrm{~nm})$, or blue $(470 \mathrm{~nm})$ instead of white light (Figure 4d,e). Red light has led to almost no catalytic improvement and the system is independent of the surfactant chain length (Figure 4e). There is a small contribution of blue light to the catalytic enhancement, but the effect does not differ for surfactants with different chain-length. In contrast to this, there is a significant effect for green light and the strongest increase in catalytic activity compared to the dark situation (182\%) can be observed for the shortest POM surfactants. Thus, an enhancement by interactions of plasmonic effects and the catalytically active POM clusters was proven.

Several possibilities exist on how promoting the catalytic activity by plasmons can occur. ${ }^{45}$ The first possibility is a local photothermal effect. ${ }^{46-48}$ The plasmonic particles heat up because of the absorption of radiation. Because dissipation of heat has to occur by means of transport through the surfactant shell attached to the gold particles, the thermal conductivity of surfactants is not high, ${ }^{48}$ and they are located in the direct vicinity of the particle surface, one cannot exclude the local temperature at the POM head group that is different from the surrounding solution. An elevated temperature at the POM head could explain the enhancement in catalytic activity. Another alternative is the occurrence of a photoelectrocatalytic effect. ${ }^{49}$ Electrons from the metallic nanoparticle are able to tunnel to suitable acceptor orbitals inducing an electrocatalytic reaction. ${ }^{50,51}$ The POM head does indeed offer such electronic levels, ${ }^{42,52}$ and the $\mathrm{W}^{\mathrm{VI}}$ centers can be reduced to $\mathrm{W}^{\mathrm{V}}$. However, we could not observe the corresponding change in the UV-VIS spectrum of the surfactant, and the mechanism of the esterification reactions involves the activation of the carboxylic group by protonation. Some reports describe that positive charge carriers (holes) can also be transferred by plasmonic particles, ${ }^{53}$ but because the POM-surfactant can hardly be oxidized, we believe that this alternative is unlikely. Besides, it was shown by our experiments that only the protonated form of the surfactant is active in catalysis. Therefore, the effect cannot be caused by a hole-mediated mechanism. The direct energy transfer from a plasmonic nanoparticle is possible by Förster resonance energy transfer or surface energy transfer, ${ }^{54}$ but because of the HOMO-LUMO gap in the UV of the POM-surfactant species, it is also unlikely that this process occurs here. Finally, the absorption of light also leads to strong electric fields directly at the surface of the plasmonic nanoparticle. The transition state of the esterification reaction was reached after protonation of the carboxylic group that has ionic character and is thus highly polar. Therefore, the dipolar coupling of this transition state can alter its energy, similar to solvent effects known for such type of reactions in organic chemistry. ${ }^{55}$ To visualize the size and shape of the plasmonic optical mode in our hybrid system, we applied finite-time-domain-difference simulations with the 0.4 $\mathrm{nm}$ grid size. We found that a gold radius of $8 \mathrm{~nm}$ and a cover layer of $2 \mathrm{~nm}$ at an effective refractive index of $n=1.2$ can approximately reproduce the measured resonance wavelength and shift. Figure 5 shows the resulting spatial intensity distribution. It covers the surfactants and adjacent reactants with the expected light concentration to a few nanometer dimensions; the peak intensity is enhanced by a factor of 7 . Lowering the energy of the transition state would result in a change of the activation barrier for the process and, consequently, an increase in the rate constant of the reaction.

From the arguments above, the two most likely candidates for explaining the observed catalytic effects are local heating effects and electric field effects. To shed some more light onto the phenomenon, we have performed a series of additional experiments. The reaction was repeated with $\mathrm{HSiC}_{5} @ \mathrm{AuNP}$ as a catalyst without light but at different temperatures (see Supporting Information Figure S13a). As expected, raising the temperature leads to an increase in TON as well up to 711 at $55{ }^{\circ} \mathrm{C}$. This is much smaller than the effect observed for the photopromoted reaction $(\mathrm{TON}=1700)$. Assuming that the temperature dependency of the reaction rate follows an Arrhenius law $\left(k \propto \exp \left(-E_{\mathrm{a}} / k T\right)\right)$, the corresponding extrapolation of the experimental data leads to a temperature of $\approx 80{ }^{\circ} \mathrm{C}$ for reaching a comparable TON. This means that the local temperature present at the POM heads would have to be of the order of $75^{\circ} \mathrm{C}$. We also checked the effect of the light intensity (see Supporting Information Figure S13b). It is seen that for doubling the light intensity, the TON is directly proportional, whereas for electric field-induced effects, the 

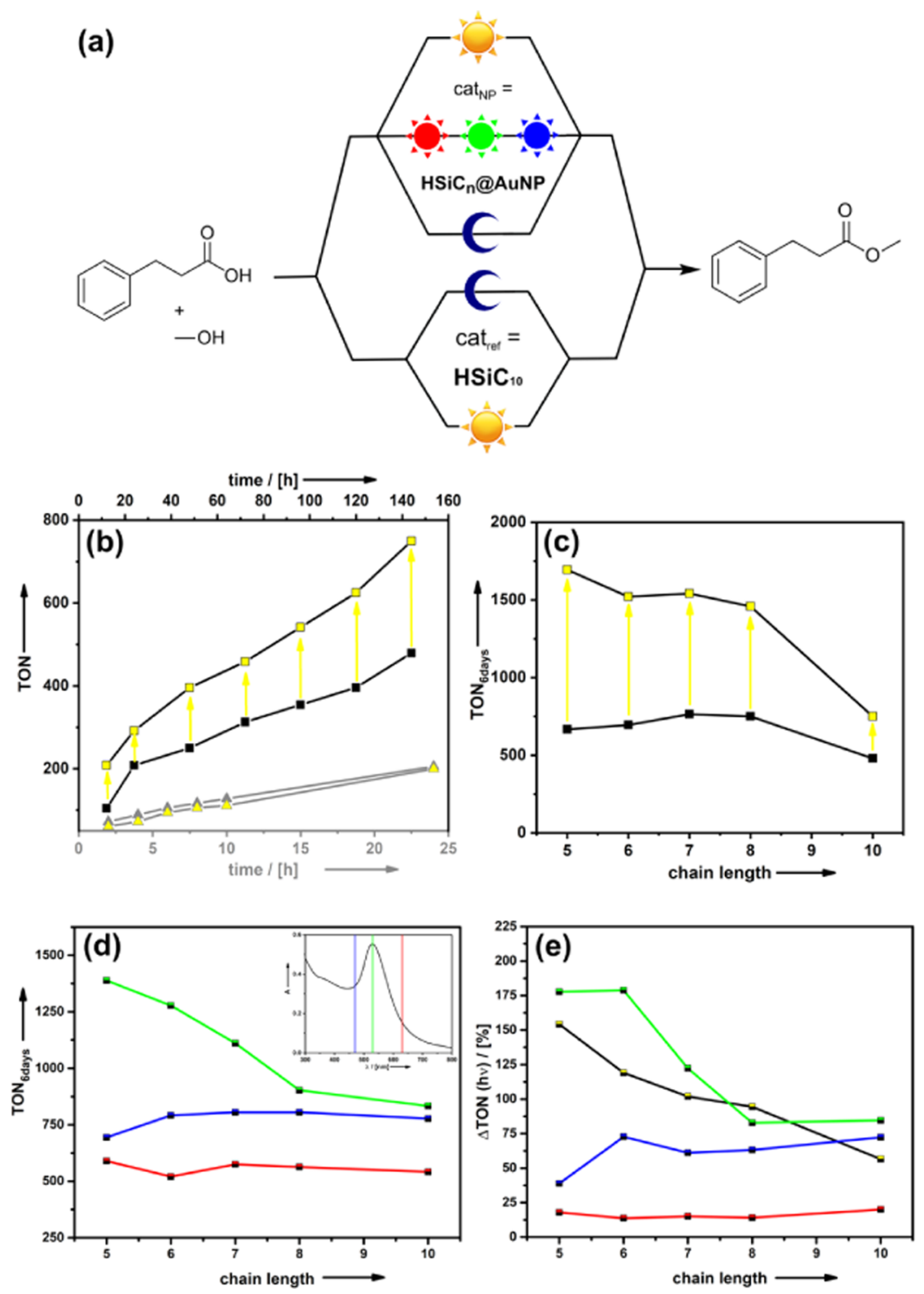

Figure 4. (a) Catalytic test reaction (isothermal conditions). (b) Turnover numbers (TONs) of $\mathrm{HSiC}_{10} @$ AuNPs (squares) and free HSiC ${ }_{10}$ (triangles) as a reference; dark conditions (black symbols) and the irradiated sample (yellow symbols). The arrows indicate the light-induced enhancement. (c) TONs after 6 days of $\mathrm{HSiC}_{n} @$ AuNPs. (d) Surfactant chain length dependence of TONs after 6 days for HSiC ${ }_{n} @$ AuNPs as a catalyst irradiated by red $(630 \mathrm{~nm})$, green $(530 \mathrm{~nm})$, and blue $(470 \mathrm{~nm})$ light. The inset shows the optical plasmon absorption band with respect to these three wavelengths. (e) Catalytic enhancement factor as a function of hydrocarbon length in $\mathrm{HSiC}_{n}$ surfactants $(n=5-10)$.

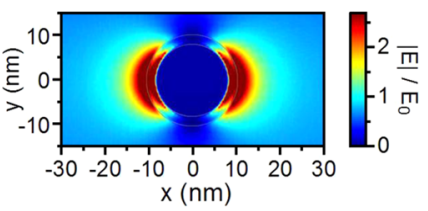

Figure 5. Plasmonic field enhancement around the nanoparticle at the resonance wavelength. A plane wave with amplitude $E \_0=1$ is propagating in the $y$-direction with polarization along the $x$-direction. Plotted is the magnitude $|E|$ of the electric field $E$ at peak time (see also the movie attached in the Supporting Information).

proportionality should only be of the order of $\sqrt{ } 2$. Therefore, we believe that the most likely explanation for the increase of catalytic activity during irradiation with light is a photothermal effect. However, it should be underlined that a precise photophysical characterization requires the application of a much more extended set of analytical techniques and theoretical calculations, which is beyond the scope of the current manuscript.

\section{CONCLUSIONS}

We have presented the synthesis of organic inorganic surfactants with an anionic polyoxometalate head group and bolaform-type architecture. A thiol group attached on the opposite side of the surfactant enabled bonding to the surface of gold nanoparticles. The acidity of the surfactants with protons as counter ions was sufficiently high to enable chemical reactions catalyzed by a Brønsted acid. The new POM-surfactant Au NP composites show catalytic activity as well, and it could be enhanced significantly by radiation with light. The cooperation between the plasmonic properties of the Au NP and the catalytic activity of the POM head group was proven because the features of the system depend strongly on the distance between POM and the surface of the nanoparticle 
adjusted by means of the surfactant length. Furthermore, catalytic enhancement strongly increased when the correct wavelength was used for radiation. There were first hints that this is because of a photothermal effect. Experiments for further photophysical characterization of the phenomenon are underway. Since the spectral position of the surface plasmon band depends on the nanoparticle size, in future, the generation of complex catalytic systems triggered by light of a particular wavelength seems achievable.

\section{METHODS}

Unless stated differently, synthesis was performed using general Schlenk techniques under an argon atmosphere. The solvents were dried according to the standard literature ${ }^{56}$ and stored under argon. All starting materials used for synthesis were purchased from commercial sources (Sigma-Aldrich or ABCR chemicals).

The lacunary polyoxometalate $(\mathrm{POM})$ cluster $\left[\mathrm{SiW}_{11} \mathrm{O}_{39}\right]^{8-}$ was synthesized according to the literature. ${ }^{57}$

Synthesis of Organic Precursor (EtO) ${ }_{3} \mathrm{SiC}_{x} \mathrm{H}_{y} \mathrm{SH}(x=4-10 ; y$ $=2 x) \cdot(E t O){ }_{3} S_{i C} H_{y} B r(1) \cdot{ }^{41}{ }^{41} \mathrm{In}$ a $250 \mathrm{~mL}$ Schlenk flask, $20 \mathrm{mmol}$ (1.0 equiv) of X-bromo-1-alkene was dissolved in $100 \mathrm{~mL}$ of dichloromethane (DCM). Next $22 \mathrm{mmol}$ (1.1 equiv) of triethoxysilane and 5 droplets of Karstedt's catalyst were added to the stirring solution. The reaction was stirred for 7 days at $40{ }^{\circ} \mathrm{C}$. Following, the solvent was removed by reduced pressure to yield a yellowish oil. The pure product was obtained by removing the residual starting materials by reduced pressure $(\sim 1 \mathrm{mbar})$ and at $90{ }^{\circ} \mathrm{C}$ for $8 \mathrm{~h}$.

Yield: 55-90\%, yellowish oil.

${ }^{1} \mathrm{H}$ NMR $\left(400 \mathrm{MHz}, \mathrm{CDCl}_{3}\right) \delta(\mathrm{ppm})=3.79(\mathrm{q}, 6 \mathrm{H}), 3.39(\mathrm{t}, 2 \mathrm{H})$; $1.90-1.30(\mathrm{~m}, 4-16 \mathrm{H}) ; 1.20(\mathrm{t}, 9 \mathrm{H}), 0.61(\mathrm{t}, 2 \mathrm{H})$.

$(E t O){ }_{3} \mathrm{SiC}_{x} \mathrm{H}_{y} \mathrm{SAC}(x=4-10 ; y=2 x)(2){ }^{58}$ In a $100 \mathrm{~mL}$ Schlenk flask, $10 \mathrm{mmol}$ (1.0 equiv) of (1) and $17 \mathrm{mmol}$ (1.7 equiv) of potassium thioacetate were dissolved in $40 \mathrm{~mL}$ of DMF. The reaction solution was heated up to $40{ }^{\circ} \mathrm{C}$ for $2 \mathrm{~h}$ with vigorous stirring. Next, the solution was cooled to room temperature and $30 \mathrm{~mL}$ of water was added. The aqueous solution was extracted three times with pentane and dried over anhydrous magnesium sulfate. The solvent of the combined organic layers was removed by reduced pressure.

Yield: $90-100 \%$, brownish oil.

${ }^{1} \mathrm{H}$ NMR (400 MHz, $\left.\mathrm{CDCl}_{3}\right) \delta(\mathrm{ppm})=3.77(\mathrm{q}, 6 \mathrm{H}), 2.84(\mathrm{t}$, $2 \mathrm{H}) ; 2.30(\mathrm{~s}, 3 \mathrm{H}) ; 1.60-1.30(\mathrm{~m}, 4-16 \mathrm{H}) ; 1.20(\mathrm{t}, 9 \mathrm{H}), 0.61(\mathrm{t}$, $2 \mathrm{H})$.

(EtO) ${ }_{3} \mathrm{SiC}_{x} \mathrm{H}_{y} \mathrm{SH}(x=4-10 ; y=2 x)$ (3). In a $100 \mathrm{~mL}$ Schlenk flask, $8 \mathrm{mmol}$ (1.0 equiv) of (2) was dissolved in $60 \mathrm{~mL}$ of ethanol. With vigorous stirring, $10.4 \mathrm{mmol}$ (1.3 equiv) of sodium borohydride was added. The reaction was heated to $40{ }^{\circ} \mathrm{C}$ for $2 \mathrm{~h}$. Next, the solution was cooled to room temperature and $30 \mathrm{~mL}$ of water was added. The aqueous solution was extracted three times with pentane and dried over anhydrous magnesium sulfate. The solvent of the combined organic layers was removed by reduced pressure.

Yield: $80-95 \%$, yellowish oil.

${ }^{1} \mathrm{H}$ NMR $\left(400 \mathrm{MHz}, \mathrm{CDCl}_{3}\right) \delta(\mathrm{ppm})=3.80(\mathrm{q}, 6 \mathrm{H}), 2.49(\mathrm{t}$, $2 \mathrm{H}) ; 1.60-1.30(\mathrm{~m}, 4-16 \mathrm{H}) ; 1.20(\mathrm{t}, 9 \mathrm{H}), 0.61(\mathrm{t}, 2 \mathrm{H})$.

Synthesis of POM-Surfactants. $\left[\mathrm{SiW}_{11} \mathrm{O}_{40}\left(\mathrm{SiC}_{x} \mathrm{H}_{y} \mathrm{SH}\right)_{2}\right](x=4-$ $10, y=2 x)(4) .{ }^{41}{ }^{41} \mathrm{In}$ a $2 \mathrm{~L}$ beaker, $1 \mathrm{mmol}$ (1.0 equiv) of powdered lacunary POM-cluster $\left(\mathrm{K}_{8}\left[\mathrm{SiW}_{11} \mathrm{O}_{39}\right]\right)$ and $7.5 \mathrm{mmol}$ (7.5 equiv) of tetramethylammonium chloride were suspended in $800 \mathrm{~mL}$ of acetonitrile. To the resulting suspension, $4.4 \mathrm{mmol}$ (4.4 equiv) of 1 $\mathrm{M}$ hydrochloric acid and $2.2 \mathrm{mmol}$ (2.2 equiv) of (3) - dissolved in $10 \mathrm{~mL}$ of DCM-were dripped into the solution. The reaction was stirred vigorously for $1 \mathrm{~d}$ at room temperature. The suspension was filtered and the solvent of the filtrate was removed by reduced pressure. The precipitate was washed with water, methanol, and diethyl ether.

Yield: $75-90 \%$ (based on the 3), white solid.

Ion exchange to the corresponding $\mathrm{H}$ - and $\mathrm{Na}-[\mathrm{Si}-$ $\left.\mathrm{W}_{11} \mathrm{O}_{40}\left(\mathrm{SiC}_{x} \mathrm{H}_{y} \mathrm{SH}\right)_{2}\right](x=4-10 ; y=2 x)$ :

Cations were exchanged to $\mathrm{Na}^{+}$or $\mathrm{H}^{+}$by slow filtration of a $2 \mathrm{mg} /$ $\mathrm{mL}$ solution of TMA-POM through a column packed with
Amberlite-IR120-H/Na. Complete exchange was confirmed via ${ }^{1} \mathrm{H}$ NMR (absence of a signal at $\delta=3.23 \mathrm{ppm}$ ).

Synthesis of POM-Surfactant Gold Nanoparticle Hybrid Systems. Gold nanoparticles were synthesized by the Turkevich method. ${ }^{43}$

Ion Exchange to the Corresponding $\mathrm{H}$-catalyst. The cations of the functionalized gold nanoparticles were changed by ion exchange chromatography. A concentrated methanol solution was filtered slowly through a column packed with Amberlite-IR120-H. The resulting suspension was concentrated by centrifugation. The nanoparticles were resuspended in $5 \mathrm{~mL}$ of methanol.

${ }^{1} \mathrm{H}$ NMR $\left(400 \mathrm{MHz}, \mathrm{CDCl}_{3}\right) \delta(\mathrm{ppm})=7.15(\mathrm{~m}, 5 \mathrm{H}), 3.58(\mathrm{~s}$, $3 \mathrm{H}), 2.86(\mathrm{t}, 2 \mathrm{H}) ; 2.57(\mathrm{t}, 2 \mathrm{H})$.

Analytical Methods. NMR measurements $\left({ }^{1} \mathrm{H},{ }^{11} \mathrm{~B},{ }^{13} \mathrm{C},{ }^{29} \mathrm{Si}\right.$, and ${ }^{31} \mathrm{P}$ ) were performed on a Varian Unity INOVA 400 Spectrometer. The ${ }^{183} \mathrm{~W}$ NMR-spectra were recorded on a Bruker Avance III 600 $\mathrm{MHz}$ Spectrometer with $10 \mathrm{~mm}$ NMR tubes. ESI-MS data were acquired on a Bruker microtof II system. The solutions were injected directly into the evaporation chamber. SAXS was acquired on a Bruker Nanostar system equipped with pinhole collimation and $\mathrm{Cu}$ $\mathrm{K} \alpha$ radiation. The samples were placed between X-ray transparent mylar foils and were measured in an evacuated chamber. For avoiding the contamination of the measurement chamber, samples were dried prior to use. TEM was acquired on a Zeiss Libra 120 system and a JEOL JEM-2200FS. The dry sample was placed directly on carboncoated copper grids. HRTEM images have been taken with a JEOL JEM-2200FS with an acceleration voltage of $200 \mathrm{kV}$. The individual surfactant samples have been prepared from aqueous solutions on copper TEM grids with a carbon coating and a net distance of 400 mesh. Dynamic light scattering (DLS) measurements were performed using a Malvern ZEN5600. UV/VIS spectroscopy was performed on a Varian Cary 100. Pictures obtained by polarization microscopy were photographed with an Olympus CX41 light microscope. Surface tensions between aqueous surfactant solutions and air were measured at $25 \pm 1{ }^{\circ} \mathrm{C}$ using a Krüss drop shape analysis DSA1 apparatus. This instrument obtains spatial coordinates of a drop edge (shape and size), which are used to calculate the surface tension. The calibration used the surface tension of pure water. Surface Tension measurements were performed using a Krüss K100 tensiometer.

Catalytic Measurements (Esterification of 3-Phenylpropionic Acid). Seventy milligrams of 3-phenylpropionic acid (0.5 mmol) were solved in $5 \mathrm{~mL}$ of catalyst. The suspension was stirred during the reaction. The reaction was irradiated by white light (power $=100 \mathrm{~W}, \lambda=400-800 \mathrm{~nm})$, red light (power $=50 \mathrm{~W}, \lambda=630 \mathrm{~nm})$, green light (power $=50 \mathrm{~W}, \lambda=530 \mathrm{~nm}$ ), or blue light (power $=50 \mathrm{~W}$, $\lambda=470 \mathrm{~nm}$ ). Reference samples were prepared without any light irradiation. All measurements were performed at isothermal conditions. All conversions were measured by ${ }^{1} \mathrm{H}$ NMR spectroscopy.

Photochemical Experiments. The experiments were performed using a self-constructed reactor setup. Ten day-light chip light emitting diodes (LEDs) (voltage $=29 \mathrm{~V}$, current $=350 \mathrm{~mA}$ ) were used for irradiation with white light. A double-walled reaction vessel and a cryostat were used for assuring isothermal conditions. The temperature of all solutions was monitored by a thermometer, for isothermal conditions. For an irradiation by red $(630 \mathrm{~nm})$, green $(530$ $\mathrm{nm})$, or blue $(470 \mathrm{~nm})$ light also, a self-constructed reactor setup was used. Therefore, 30 RGB chip LEDs were used. These were cooled by air. Overall a power of $50 \mathrm{~W}$ was used (voltage $=9 \mathrm{~V}$, current $=5.5 \mathrm{~A}$ ) for the experiments. The temperature of all solutions was monitored by a thermometer, for isothermal conditions.

\section{ASSOCIATED CONTENT}

\section{Supporting Information}

The Supporting Information is available free of charge on the ACS Publications website at DOI: 10.1021/acsami.9b03727.

Photochemical set-up (including experimental details), molecular characterization (ESI-MS, NMR), surface activity and TEM and EDX-data of the synthesized POM surfactants, TEM images of Au NP synthesized 
using POM surfactants, acidity measurement of H-POM surfactants, NMR measurements and conversion table for catalytic tests, UV-VIS spectra of POM surfactants and POM@AuNP, UV-VIS spectra and TEM images (including EDX line scans) of the used catalyst (before and after catalysis) (PDF)

Plotted is the magnitude $|E|$ of the electric field $E$ at peak time (MPG)

\section{AUTHOR INFORMATION}

\section{Corresponding Author}

*E-mail: sebastian.polarz@uni-konstanz.de.

\section{ORCID}

Sebastian Polarz: 0000-0003-1651-4906

\section{Author Contributions}

This manuscript was written through contributions of all authors. All authors have given approval to the final version of the manuscript. SS has prepared and characterized the surfactants. BT has performed analytical measurements. SSi has constructed the photochemical reactor. $\mathrm{KH}$ has performed titration experiments. ST has performed HRTEM measurements. PB performed the calculation of the plasmonic modes. $\mathrm{SP}$ designed the research and wrote the paper.

\section{Notes}

The authors declare no competing financial interest.

\section{ACKNOWLEDGMENTS}

The current research was funded by an ERC consolidator grant (I-SURF; project 614606). SFB-1214 is acknowledged for providing analytical methods in the particle analysis center (PAC, project $\mathrm{Z1}$ ).

\section{ABBREVIATIONS}

POM, polyoxometalate

Au-NP, gold nanoparticle

SAMS, self-assembled monolayers

TMA, tetramethylammonium

ESI-MS, electrospray-ionization mass spectrometry

NMR, nuclear magnetic resonance

TMASiC $_{10},\left(\mathrm{~N}\left(\mathrm{CH}_{3}\right)_{4}\right)_{4}\left[\mathrm{SiW}_{11} \mathrm{O}_{40}\right]\left(\mathrm{Si}\left(\mathrm{CH}_{2}\right)_{10} \mathrm{SH}\right)_{2}$

DLS, dynamic light scattering

(HR-)TEM, (high-resolution) transmission electron microscopy

EDX, energy-dispersive X-ray spectroscopy

TON, turnover number

VIS, visible

PEG-SH, poly-ethylene-glycol-thiol

\section{REFERENCES}

(1) Dwars, T.; Paetzold, E.; Oehme, G. Reactions in Micellar Systems. Angew. Chem., Int. Ed. 2005, 44, 7174-7199.

(2) Grzelczak, M.; Perez-Juste, J.; Mulvaney, P.; Liz-Marzan, L. M. Shape Control in Gold Nanoparticle Synthesis. Chem. Soc. Rev. 2008, 37, 1783-1791.

(3) Czajka, A.; Hazell, G.; Eastoe, J. Surfactants at the Design Limit. Langmuir 2015, 31, 8205-8217.

(4) Brown, P.; Butts, C. P.; Eastoe, J. Stimuli-Responsive Surfactants. Soft Matter 2013, 9, 2365-2374.

(5) Bijlard, A. C.; Wald, S.; Crespy, D.; Taden, A.; Wurm, F. R.; Landfester, K. Functional Colloidal Stabilization. Adv. Mater. Interfaces 2017, 4, No. 1600443.

(6) Polarz, S.; Kunkel, M.; Donner, A.; Schlötter, M. Added-Value Surfactants. Chem. - Eur. J. 2018, 24, 18842.
(7) Polarz, S.; Landsmann, S.; Klaiber, A. Hybrid Surfactant Systems with Inorganic Constituents. Angew. Chem., Int. Ed. 2014, 53, 946954.

(8) Tauster, S. J. Strong Metal-Support Interactions. Acc. Chem. Res. 1987, 20, 389-394.

(9) Linic, S.; Aslam, U.; Boerigter, C.; Morabito, M. Photochemical Transformations on Plasmonic Metal Nanoparticles. Nat. Mater. 2015, 14, 567-576.

(10) Lang, X. J.; Chen, X. D.; Zhao, J. C. Heterogeneous Visible Light Photocatalysis for Selective Organic Transformations. Chem. Soc. Rev. 2014, 43, 473-486.

(11) Hou, W.; Cronin, S. B. A Review of Surface Plasmon Resonance-Enhanced Photocatalysis. Adv. Funct. Mater. 2013, 23, $1612-1619$.

(12) Ren, X.; Cao, E.; Lin, W.; Song, Y.; Liang, W.; Wang, J. Recent Advances in Surface Plasmon-Driven Catalytic Reactions. RSC Adv. 2017, 7, 31189-31203.

(13) Lemos de Souza, M.; Pereira dos Santos, D.; Corio, P. Localized Surface Plasmon Resonance Enhanced Photocatalysis: An Experimental and Theoretical Mechanistic Investigation. RSC Adv. 2018, 8, 28753-28762.

(14) Solarska, R.; Bienkowski, K.; Zoladek, S.; Majcher, A.; Stefaniuk, T.; Kulesza, P. J.; Augustynski, J. Enhanced Water Splitting at Thin Film Tungsten Trioxide Photoanodes Bearing Plasmonic Gold-Polyoxometalate Particles. Angew. Chem., Int. Ed. 2014, 53, 14196-14200.

(15) Kozhevnikov, I. V. Catalysis by Heteropoly Acids and Multicomponent Polyoxometalates in Liquid-Phase Reactions. Chem. Rev. 1998, 98, 171-198.

(16) Proust, A.; Thouvenot, R.; Gouzerh, P. Functionalization of Polyoxometalates: Towards Advanced Applications in Catalysis and Materials Science. Chem. Commun. 2008, 1837-1852.

(17) Mitchell, S. G.; de la Fuente, J. M. The Synergistic Behavior of Polyoxometalates and Metal Nanoparticles: From Synthetic Approaches to Functional Nanohybrid Materials. J. Mater. Chem. 2012, 22, 18091-18100.

(18) Zhang, B.; Yin, P.; Haso, F.; Hu, L.; Liu, T. Soft Matter Approaches for Enhancing the Catalytic Capabilities of Polyoxometalate Clusters. J. Cluster Sci. 2014, 25, 695-710.

(19) Ito, T. Inorganic-Organic Hybrid Surfactant Crystals: Structural Aspects and Functions. Crystals 2016, 6, 24.

(20) Song, Y. F.; Tsunashima, R. Recent Advances on Polyoxometalate-Based Molecular and Composite Materials. Chem. Soc. Rev. 2012, 41, 7384-7402.

(21) Song, Y. F.; Long, D. L.; Ritchie, C.; Cronin, L. Nanoscale Polyoxometalate-Based Inorganic/Organic Hybrids. Chem. Rec. 2011, 11, 158-171.

(22) Long, D. L.; Tsunashima, R.; Cronin, L. Polyoxometalates: Building Blocks for Functional Nanoscale Systems. Angew. Chem., Int. Ed. 2010, 49, 1736-1758.

(23) Proust, A.; Matt, B.; Villanneau, R.; Guillemot, G.; Gouzerh, P.; Izzet, G. Functionalization and Post-Functionalization: A Step Towards Polyoxometalate-Based Materials. Chem. Soc. Rev. 2012, 41, 7605-7622.

(24) Verhoeff, A. A.; Kistler, M. L.; Bhatt, A.; Pigga, J.; Groenewold, J.; Klokkenburg, M.; Veen, S.; Roy, S.; Liu, T. B.; Kegel, W. K. Charge Regulation as a Stabilization Mechanism for Shell-Like Assemblies of Polyoxometalates. Phys. Rev. Lett. 2007, 99, No. 066104.

(25) Pradeep, C. P.; Misdrahi, M. F.; Li, F. Y.; Zhang, J.; Xu, L.; Long, D. L.; Liu, T. B.; Cronin, L. Synthesis of Modular "InorganicOrganic-Inorganic" Polyoxometalates and Their Assembly into Vesicles. Angew. Chem., Int. Ed. 2009, 48, 8309-8313.

(26) Yin, P. C.; Pradeep, C. P.; Zhang, B. F.; Li, F. Y.; Lydon, C.; Rosnes, M. H.; Li, D.; Bitterlich, E.; Xu, L.; Cronin, L.; Liu, T. B. Controllable Self-Assembly of Organic-Inorganic Amphiphiles Containing Dawson Polyoxometalate Clusters. Chem. - Eur. J. 2012, 18, $8157-8162$

(27) Yin, P. C.; Wu, P. F.; Xiao, Z. C.; Li, D.; Bitterlich, E.; Zhang, J.; Cheng, P.; Vezenov, D. V.; Liu, T. B.; Wei, Y. G. A Double-Tailed 
Fluorescent Surfactant with a Hexavanadate Cluster as the Head Group. Angew. Chem., Int. Ed. 2011, 50, 2521-2525.

(28) Judeinstein, P.; Deprun, C.; Nadjo, L. Synthesis and Multispectroscopic Characterization of Organically Modified Polyoxometalates. J. Chem. Soc., Dalton Trans. 1991, 8, 1991-1997.

(29) Kim, G. S.; Hagen, K. S.; Hill, C. L. Synthesis, Structure, Spectroscopic Properties, and Hydrolytic Chemistry of Organophosphonoyl Polyoxotungstates of Formula $[\mathrm{C} 6 \mathrm{~h} 5 \mathrm{p}(\mathrm{O})] 2 \mathrm{xn}$ +W11o39(8-N)- (Xn+ = P5+, Si4+). Inorg. Chem. 1992, 31, 53165324.

(30) Landsmann, S.; Lizandara-Pueyo, C.; Polarz, S. A New Class of Surfactants with Multinuclear, Inorganic Head Groups. J. Am. Chem. Soc. 2010, 132, 5315-5321.

(31) Giner-Casares, J. J.; Brezesinski, G.; Möhwald, H.; Landsmann, S.; Polarz, S. Polyoxometalate Surfactants as Unique Molecules for Interfacial Self-Assembly. J. Phys. Chem. Lett. 2012, 3, 322-326.

(32) Klaiber, A.; Landsmann, S.; Loffler, T.; Polarz, S. Fourfold Action of Surfactants with Superacid Head Groups: PolyoxometalateSilicone Nanocomposites as Promising Candidates for ProtonConducting Materials. New J. Chem. 2016, 40, 919-922.

(33) Klaiber, A.; Lanz, C.; Landsmann, S.; Gehring, J.; Drechsler, M.; Polarz, S. Maximizing Headgroup Repulsion: Hybrid Surfactants with Ultrahighly Charged Inorganic Heads and Their Unusual SelfAssembly. Langmuir 2016, 32, 10920-10927.

(34) Love, J. C.; Estroff, L. A.; Kriebel, J. K.; Nuzzo, R. G.; Whitesides, G. M. Self-Assembled Monolayers of Thiolates on Metals as a Form of Nanotechnology. Chem. Rev. 2005, 105, 1103-1169.

(35) Jadzinsky, P. D.; Calero, G.; Ackerson, C. J.; Bushnell, D. A.; Kornberg, R. D. Structure of a Thiol Monolayer-Protected Gold Nanoparticle at 1.1 Angstrom Resolution. Science 2007, 318, 430433.

(36) Mayer, C. R.; Neveu, S.; Cabuil, V. A Nanoscale Hybrid System Based on Gold Nanoparticles and Heteropolyanions. Angew. Chem. 2002, 114, 519-521.

(37) Hegde, S.; Joshi, S.; Mukherjee, T.; Kapoor, S. Formation of Gold Nanoparticles Via a Thiol Functionalized Polyoxometalate. Mater. Sci. Eng. C 2013, 33, 2332-2337.

(38) De bruyn, M.; Neumann, R. Stabilization of Palladium Nanoparticles by Polyoxometalates Appended with Alkylthiol Tethers and Their Use as Binary Catalysts for Liquid Phase Aerobic Oxydehydrogenation. Adv. Synth. Catal. 2007, 349, 1624-1628.

(39) Hoyle, C. E.; Bowman, C. N. Thiol-Ene Click Chemistry. Angew. Chem., Int. Ed. 2010, 49, 1540-1573.

(40) Judeinstein, P.; Deprun, C.; Nadjo, L. Synthesis and Multispectroscopic Characterization of Organically Modified Polyoxometalates. J. Chem. Soc., Dalton Trans. 1991, 8, 1991-1997.

(41) Landsmann, S.; Luka, M.; Polarz, S. Bolaform Surfactants with Polyoxometalate Head Groups and Their Assembly into Ultra-Small Monolayer Membrane Vesicles. Nat. Commun. 2012, 3, No. 1299.

(42) Klaiber, A.; Polarz, S. Passing Current through Electrically Conducting Lyotropic Liquid Crystals and Micelles Assembled from Hybrid Surfactants with $\Pi$-Conjugated Tail and Polyoxometalate Head. ACS Nano 2016, 10, 10041-10048.

(43) Turkevich, J.; Stevenson, P. C.; Hillier, J. A Study of the Nucleation and Growth Processes in the Synthesis of Colloidal Gold. Discuss. Faraday Soc. 1951, 11, 55-75.

(44) Cheon, C. H.; Yamamoto, H. Super Bronsted Acid Catalysis. Chem. Commun. 2011, 47, 3043-3056.

(45) Xiao, M. D.; Jiang, R. B.; Wang, F.; Fang, C. H.; Wang, J. F.; Yu, J. C. Plasmon-Enhanced Chemical Reactions. J. Mater. Chem. A 2013, 1, 5790-5805.

(46) Jaque, D.; Martínez Maestro, L.; del Rosal, B.; Haro-Gonzalez, P.; Benayas, A.; Plaza, J. L.; Martín Rodríguez, E.; García Solé, J. Nanoparticles for Photothermal Therapies. Nanoscale 2014, 6, 94949530.

(47) Ekici, O.; Harrison, R. K.; Durr, N. J.; Eversole, D. S.; Lee, M.; Ben-Yakar, A. Thermal Analysis of Gold Nanorods Heated with Femtosecond Laser Pulses. J. Phys. D: Appl. Phys. 2008, 41, No. 185501.
(48) Wang, F.; Li, C. H.; Chen, H. J.; Jiang, R. B.; Sun, L. D.; Li, Q.; Wang, J. F.; Yu, J. C.; Yan, C. H. Plasmonic Harvesting of Light Energy for Suzuki Coupling Reactions. J. Am. Chem. Soc. 2013, 135, $5588-5601$.

(49) Robatjazi, H.; Bahauddin, S. M.; Doiron, C.; Thomann, I. Direct Plasmon-Driven Photoelectrocatalysis. Nano Lett. 2015, 15, 6155-6161.

(50) Winkler, J. R.; Gray, H. B. Long-Range Electron Tunneling. J. Am. Chem. Soc. 2014, 136, 2930-2939.

(51) Wold, D. J.; Haag, R.; Rampi, M. A.; Frisbie, C. D. Distance Dependence of Electron Tunneling through Self-Assembled Monolayers Measured by Conducting Probe Atomic Force Microscopy: Unsaturated Versus Saturated Molecular Junctions. J. Phys. Chem. B 2002, 106, 2813-2816.

(52) Klaiber, A.; Kollek, T.; Cardinal, S.; Hug, N.; Drechsler, M.; Polarz, S. Electron Transfer in Self-Assembled Micelles Built by Conductive Polyoxometalate-Surfactants Showing Battery-Like Behavior. Adv. Mater. Interfaces 2018, 5, No. 1701430.

(53) Govorov, A. O.; Zhang, H.; Gun'ko, Y. K. Theory of Photoinjection of Hot Plasmonic Carriers from Metal Nanostructures into Semiconductors and Surface Molecules. J. Phys. Chem. C 2013, $117,16616-16631$.

(54) Zhang, X.; A. Gerard, V.; Gun'ko, Y.; Lesnyak, V.; Gaponik, N.; Susha, A.; L. Rogach, A.; Bradley, L. In Large Energy Transfer Distance to a Plane of Gold Nanoparticles, 2012 14th International Conference on Transparent Optical Networks (ICTON); IEEE, 2012; pp 1-4.

(55) Riechert, O.; Husham, M.; Sadowski, G.; Zeiner, T. Solvent Effects on Esterification Equilibria. AIChE J. 2015, 61, 3000-3011.

(56) Armarego, W. L. F.; Perrin, D. D. Purification of Laboratory Chemicals, 4th Paperback ed.; Butterworth-Heinemann: Oxford, 1997.

(57) Téazéa, A.; Hervéa, G.; Finke, R. G.; Lyon, D. K. A-, B-, and ГDodecatungstosilicic Acids: Isomers and Related Lacunary Compounds. Inorg. Synth. 1990, 85-96.

(58) Bordwell, F.; Hewett, W. Notes - Synthesis from Thiolacetates. I. Synthesis of Alkanesulfonyl Chlorides. J. Org. Chem. 1957, 22, 980981. 